\title{
Trade-Off Between Carbon Dioxide Emissions and Logistics Costs Based on Multiobjective Optimization
}

\author{
Nam Seok Kim, Milan Janic, and Bert van Wee
}

\begin{abstract}
This paper examines the relationship between the freight transport costs and the carbon dioxide $\left(\mathrm{CO}_{2}\right)$ emissions in given intermodal and truckonly freight networks. When the trade-off, which is represented as the relationship, is changed, the freight mode share and route choice are also modified. To show the ever changing trade-off and mode and route choice, a decision-support tool was developed. The given intermodal freight networks represent different freight combinations (i.e., a truckonly system, a rail-based intermodal system, and a short sea-based intermodal system). Because $\mathrm{CO}_{2}$ constraints in logistics markets will need to be realized in the near future, a modal shift in freight transportation could be expected to reduce the $\mathrm{CO}_{2}$ emissions within the reasonable cost and time constraints. The technique of multiobjective optimization is used as the core of the decision-support tool for clarifying the relationship. The tool that was developed is applied to a simplified freight transport network connecting two large European ports: the Port of Rotterdam (the Netherlands) and the Port of Gdansk (Poland). The initial solution, based on the minimization of freight costs, shows that the mode share of freight is local and regional freight transportation situations, whereas the other solutions balanced with $\mathrm{CO}_{2}$ emissions show that the mode share is changed into an intermodal freight system, which is based on a hub-and-spoke network. In considering the changing demands and capacities of freight systems, five scenarios are tested to examine the impact of mode and route change on the trade-off. The results of scenario analyses show that the trade-off is significantly influenced by the demands and capacities of systems.
\end{abstract}

In most logistics systems, the minimization of cost and time performance has always been the main objective. Efficiency-oriented logistics systems have created a high degree of dependence on the truck-only system (the road freight market share amounts to about $44 \%$ in the European Union) $(1,2)$. However, over the same time period, road freight transportation has been one of the most rapidly growing contributors to carbon dioxide $\left(\mathrm{CO}_{2}\right)$ emissions, although the $\mathrm{CO}_{2}$ emissions from other contributors have decreased, albeit rather slowly, over the past 10 years $(1,3)$. Consequently, to reduce the $\mathrm{CO}_{2}$ emissions from road freight transportation in Europe, international

N. S. Kim and M. Janic, Department of Transport and Infrastructure, OTB Research Institute, Delft University of Technology, Jaffalaan 9, 2628 BX Delft, Netherlands. B. van Wee, Department of Transport and Logistic, Faculty of Technology, Policy and Management, Delft University of Technology, Delft, Netherlands. Corresponding author: N. S. Kim, n.s.kim@tudelft.nl.

Transportation Research Record: Journal of the Transportation Research Board, No. 2139, Transportation Research Board of the National Academies, Washington, D.C., 2009, pp. 107-116.

DOI: $10.3141 / 2139-13$ organizations as well as national and local governments have designed policies that aim to increase the market shares of the non-road freight transportation modes, focusing on intermodal or multimodal freight transportation systems $(4,5)$. A research question is then raised: What is the desired (well-balanced) freight mode share? To what extent should intermodal freight systems be desirable to ensure a market for freight (and in this study, container transportation in particular is studied) and to reduce $\mathrm{CO}_{2}$ emissions from freight transportation? This study attempts to answer these questions by clarifying the relationship between the costs and the $\mathrm{CO}_{2}$ emissions of different modes.

To estimate the share of particular freight transportation modes, a decision-support tool based on the multiobjective optimization problem was developed. The detailed outcome expected is the ever changing network assignment solution for each solution as well as the trade-off curve, which consists of a certain number of assignment solutions. This outcome may be an answer to the research question asked above. The tool is applied to a simplified network consisting of two hubs and four spokes (i.e., two nodes for hubs and four nodes for local shippers and consignees).

\section{MULTIMODAL HUB-AND-SPOKE NETWORK REPRESENTATION}

This section describes the representation of a multimodal hub-andspoke network, which consists of two kinds of nodes, hub cities and local cities, and two kinds of arcs, internal flows and external flows. Figure $1 a$ illustrates the internal and external flows. The internal flows consist of explicit and implicit internal flows. Explicit internal flows indicate the flows from or to any node in the network, excluding a dummy node, which is the representative node for other cities in the network region. Implicit internal flows, which influence the network but which are not specifically expressed in the network, indicate the flows from and to the dummy node. For example, the implicit internal flows might use long haul in an intermodal freight system, but the destination is not explicitly indicated in the network region. The external flows are coming or outgoing from or to some place outside of the network. Specifically, if the supply of node 1 $\left(O_{1}\right)$ is the sum of $X_{\text {lexternal }}, X_{12}$, and $X_{\text {ldummy }}$, only $\mathrm{X}_{12}$ is considered. This is illustrated in Figure $1 b$, in which one more hub city and some more local cities are added to the representation in Figure 1a. The arcs do not represent the homogeneous infrastructure (e.g., highways). For example, $\mathrm{ARC}_{\text {hublhub2 }}$ can be a railway, a short sea shipping line, or a roadway. $X_{\text {hublexternal }}$ can be short or deep sea shipping lines. Figure $1 c$ presents the comprehensive network by consideration of all possible modes in the network. For example, the long haulage from Hub 1 to Hub 2 flows on $\mathrm{ARC}_{\text {hublhub2 }}$ and is the sum- 


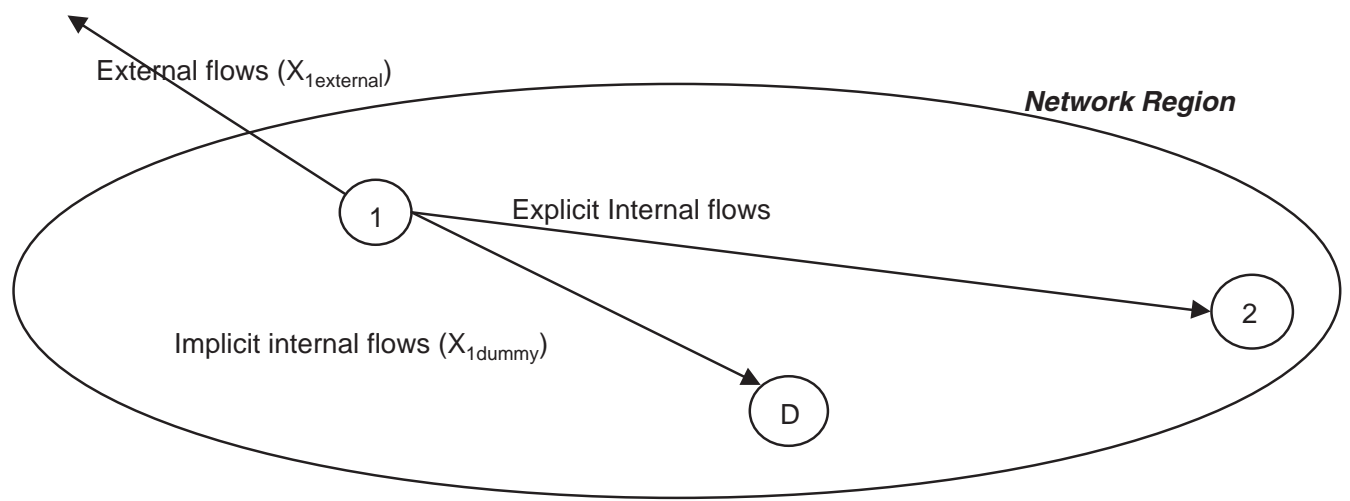

(a)

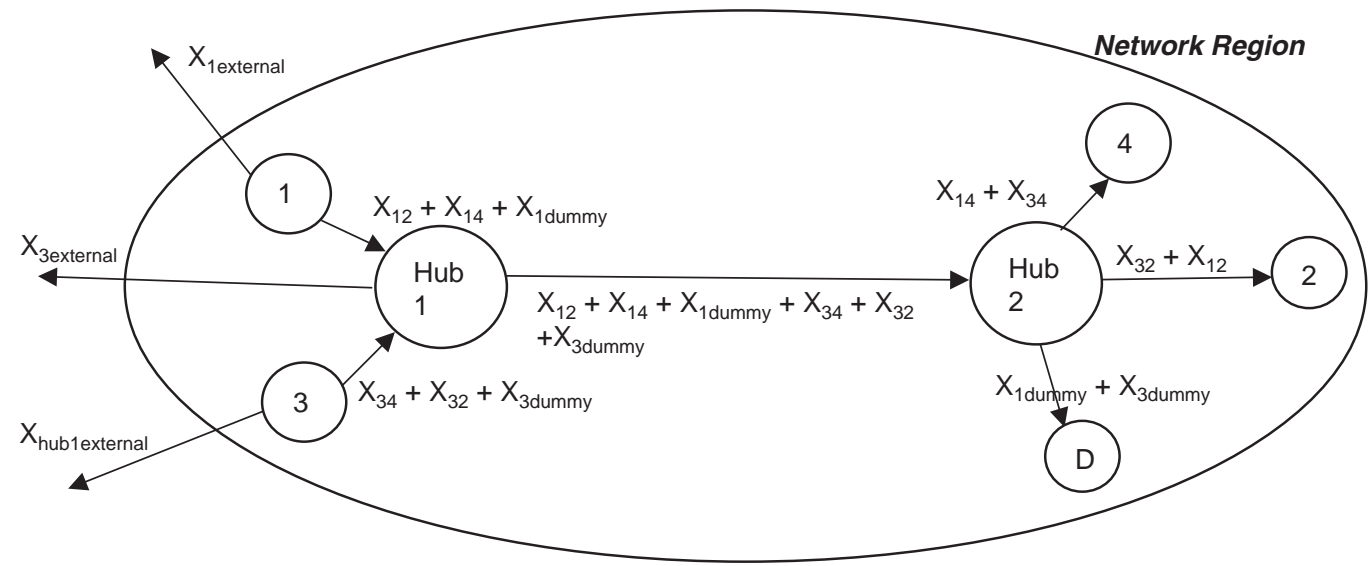

(b)

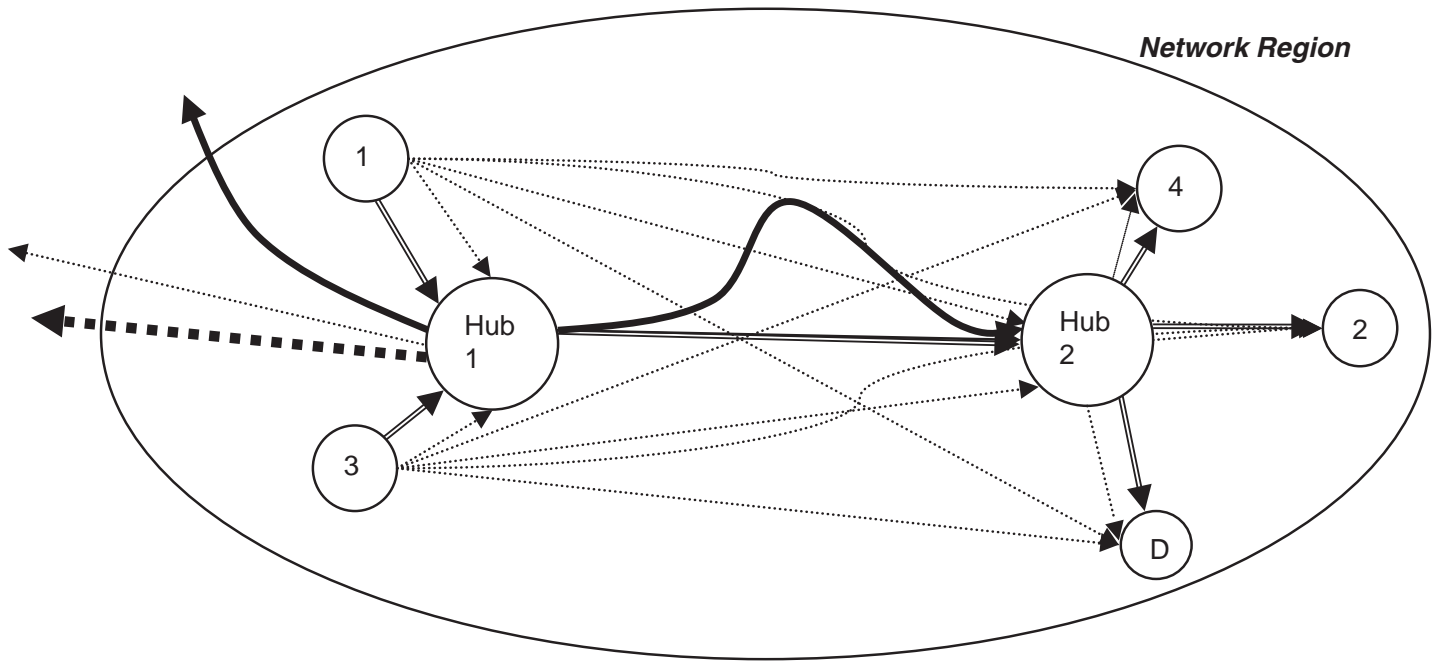

(c)

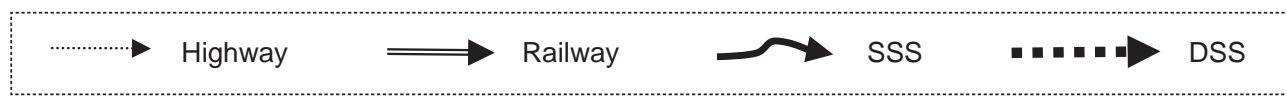

FIGURE 1 Freight network representation: (a) internal and external flows, $(b)$ hub-and-spoke network, and (c) multimodal freight network. 
mation of the flows of three systems: truck, indicated with a superscript $1\left(X^{1}\right)$; the rail intermodal system, designated 1 ; and short sea shipping, designated 3. Specifically, $X_{34}+X_{32}+X_{3 \text { dummy }}=\left(X_{34}^{1}+X_{32}^{1}\right.$ $\left.+X_{3 \text { dummy }}^{1}\right)+\left(X_{34}^{1}+X_{32}^{1}+X_{3 \text { dummy }}^{1}\right)+\left(X_{34}^{3}+X_{32}^{3}+X_{3 \text { dummy }}^{3}\right)$.

For the truck-only system, each local shipper or consignee can send and receive flows directly by truck. For example, the linear line from Node 1 to Node 4 is $X_{14}^{1}$. All the other flows in the network region can be presented in the same way. Note that the basic unit of freight transportation is "system" instead of "mode" in Figure $1 c$ to represent both truck-only systems and intermodal (multimodal) systems. Thus, drayage and terminal transshipments are regarded as parts of intermodal systems.

\section{MULTIOBJECTIVE OPTIMIZATION FOR FREIGHT COST AND $\mathrm{CO}_{2}$ EMISSIONS}

The multiobjective optimization model is used as the core of the decision-support tool to find the optimal freight system assignment (e.g., a truck-only system, a rail-based intermodal system, and a vessel-based short sea system) and to estimate the trade-off between freight costs and $\mathrm{CO}_{2}$ emissions. Two types of multiobjective optimization problems are applicable: preference-based and ideal problems (i.e., cooperative and competing, respectively) (6). The core of preference-based optimization problems is the internalization of $\mathrm{CO}_{2}$ emissions in the objective function. Thus, the solution is similar to the one for single optimization problems. However, the ideal multiobjective optimization problem considers two issues (i.e., in this case, freight costs and $\mathrm{CO}_{2}$ emissions) separately and estimates their relationship (i.e., the trade-off). The relationship can be drawn as a trade-off graph and is called a pareto optimal solution (6). The problem with the preference-based approach is that it is extremely difficult to estimate the price of $\mathrm{CO}_{2}$ (e.g., by use of a conversion factor such as the number of euros per kilogram of $\mathrm{CO}_{2}$ ). Nevertheless, most of the previous research has treated this issue by using constant conversion factors expressed in monetary terms in the context of external costs and, accordingly, has remodeled such a multiobjective optimization problem as a single optimization problem. Janic (7) and Chang et al. (8), for example, use the concept of external costs, including air pollution, congestion, noise, and traffic accidents, in the optimization model. However, as mentioned above, the research community has not fully agreed on the conversion factor (i.e., the external cost) to be used. In other words, even though $\mathrm{CO}_{2}$ emissions might be treated as a component of the external costs, conversion of the emission into monetary terms should be done carefully. For this reason, the ideal multiobjective optimization approach, which is more flexible, was chosen for use in this study. In addition, as shown later, the conversion factor can conversely be approximated by this approach once the trade-off has been estimated. The ideal multiobjective is presented in its general form and is then applied to the relationship between cost and $\mathrm{CO}_{2}$ emissions in freight transportation systems in the following sections.

\section{General Multiobjective Optimization Problem and Pareto Optimal Solution}

Minimize-maximize $f_{m}(\mathbf{x})$, where $m=1,2, \ldots, M$

such that

$g_{j}(\mathbf{x}) \geq 0$, where $j=1,2, \ldots, J$ $h_{k}(\mathbf{x})=0$, where $k=1,2, \ldots, K$

$x_{i}^{(L)} \leq x_{i} \leq x_{i}^{(U)}$, where $i=1,2, \ldots, N$

where

$\mathbf{x}=$ vector of $n$ decision variables, where $\mathbf{x}=\left(x_{1}\right.$, $\left.x_{2}, \ldots, x_{n}\right)^{T}$

$x_{i}^{(L)}$ and $x_{i}^{(U)}=$ lower and upper bounds of $x_{i}$, respectively; and $g_{j}(\mathbf{x})$ and $h_{k}(\mathbf{x})=$ constraint functions of inequality $J$ and equality $K$, respectively.

The terms $x_{i}^{(L)}$ and $x_{i}^{(U)}$ demarcate a decision variable space, $D$. Thus, the number of axes of a decision variable space is $N$. The multiobjective space, $Z$, is the crucial difference between a single objective optimization problem and a multiobjective optimization problem because the latter has multidimensional space [more details are provided elsewhere (6)].

A pareto optimal solution is defined as follows: "a solution (call it $A$ ) to a multi-objective problem is Pareto optimal if no other feasible solution is at least as good as $A$ with respect to every objective and strictly better than $A$ with respect to at least one objective" (9).

\section{Relationship Between Cost and $\mathrm{CO}_{2}$ Emissions}

The aim is to determine an appropriate freight modal split that ensures minimum freight costs and the minimum level of $\mathrm{CO}_{2}$ emissions, subject to the demand and the capacity. Thus, the final solution might not be a single point but a curve or a line. The multiobjective optimization problem was found to be highly suitable for the aim of this study. The objective functions in the problem are to minimize the total system operational costs and the quantities of $\mathrm{CO}_{2}$ emissions. The optimization constraints are $(a)$ the flow conservation constraints, $(b)$ the freight system availability constraints, $(c)$ intermodal freight conservation, $(d)$ the nonnegativity constraints, and $(e)$ the $\mathrm{CO}_{2}$ emission restriction constraints, defined as a quota, for both the particular routes and the transshipment points. Highlighting the $\mathrm{CO}_{2}$ quota, Kim and Janic recently developed $\mathrm{CO}_{2}$ limitations on the basis of the Kyoto Protocol and other traffic characteristics (10). The quota is defined as the fixed target quantity assigned to the freight transportation after consideration of all other sources of emissions of $\mathrm{CO}_{2}$, such as from passenger transportation sharing the same transportation infrastructure. However, the $\mathrm{CO}_{2}$ quota in this paper is defined as the relative magnitude updated iteratively from the initial $\mathrm{CO}_{2}$ mass when the freight cost is minimized.

The notation used in the model is as follows:

$V=$ set of nodes, that is, the origins and destinations of the freight transportation flows;

$A=$ set of routes connecting the origin and destination nodes of the freight flows;

$K=$ set of freight transportation systems serving the given freight flows in a given region;

$O(k), k \in K=$ set of origins of freight system $k$;

$D(k), k \in K=$ set of destinations of freight system $k$; $o_{i j}^{k},(i, j) \in A, k \in K=$ demand of freight system $k$ from point $i$ to point $j$;

$u^{k},(i, j) \in A, k \in K=$ service capacity of freight system $k$ on the system; 


$$
\begin{aligned}
x_{i j}^{k},(i, j) \in A, k \in K= & \text { flow of freight system } k \text { on the route } \\
& (i, j) \text { (i.e., the decision variable); } \\
C_{i j}^{k}\left(x_{i j}^{k}\right),(i, j) \in A, k \in K= & \begin{array}{l}
\text { cost for transporting } x_{i j}^{k} \text { flow units by } \\
\text { freight system } k \text { on the route }(i, j) \text { (in } \\
\text { dollars per ton); }
\end{array} \\
Q_{i j}^{k}\left(x_{i j}^{k}\right),(i, j) \in A, k \in K= & \mathrm{CO}_{2} \text { emissions from the transportation } \\
& \text { system } k \text { on route (i,j) (in tons); } \\
Q_{i}^{k}\left(x_{i}^{k}\right), i \in T(k), k \in K= & \begin{array}{l}
\mathrm{CO}_{2} \text { emissions at transshipment point } \\
k \text { (tons); and }
\end{array} \\
B_{i j},(i, j) \in A= & \mathrm{CO}_{2} \text { emissions quota for the route }(i, j) \\
& \text { including terminal operations (in tons). }
\end{aligned}
$$

It is notable that $A$ in the notation above is not the arc that connects individual nodes. The route can be a series of arcs.

Although objective functions and the related constraints are not purely linear if the related freight costs and $\mathrm{CO}_{2}$ emissions are fully formulated, this study attempts to express them in a linear form and simplify the problem to avoid unnecessary complexities. Thus, the parameter estimation of $C_{i j}^{k}$ and $Q_{i j}^{k}$ is indeed crucial to finding the approximation of the pareto optimal solution. The simplified objective functions and constraints are presented below.

Objective Function $1\left(Z_{1}\right)$ is based on the total transportation cost:

$$
Z_{1}=\min \sum_{k \in K} \sum_{(i, j) \in A} C_{i j}^{k} x_{i j}^{k}
$$

Objective Function $2\left(Z_{2}\right)$ is based on the $\mathrm{CO}_{2}$ emissions:

$$
Z_{2}=\min \left[\sum_{k \in K} \sum_{(i, j) \in A} Q_{i j}^{k} x_{i j}^{k}+\sum_{k \in K} \sum_{i \in V} Q_{i}^{k} x_{i}^{k}+\sum_{k \in K} \sum_{j \in V} Q_{j}^{k} x_{j}^{k}\right]
$$

subject to

Flow conservation constraints:

$$
\sum_{\{j \in V:(i, j) \in A\}} x_{i j}^{k}=o_{i j}^{k},(i, j) \in A, k \in K
$$

Freight mode availability constraints:

$$
\sum_{\{j \in V:(i, j) \in A\}} x_{i j}^{k} \leq u^{k}, i \in V, k \in K
$$

Intermodal freight conservation constraints:

$$
\begin{gathered}
\sum_{\{j \in V:(i, j) \in A\}} x_{i j}^{k} \leq u^{k}, k=2 \text { and } 4 \\
\sum_{\{j \in V:(i, j) \in A\}} x_{i j}^{k} \leq u^{k}, k=3 \text { and } 5
\end{gathered}
$$

Nonnegativity constraints:

$$
x_{i j}^{k} \geq 0
$$

$\mathrm{CO}_{2}$ emission quota constraints:

$$
\left[\sum_{k \in K} \sum_{(i, j) \in A} Q_{i j}^{k} x_{i j}^{k}+\sum_{k \in K} \sum_{i \in V} Q_{i}^{k} x_{i}^{k}+\sum_{k \in K} \sum_{j \in V} Q_{j}^{k} x_{j}^{k}\right] \leq B_{i j},(i, j) \in A, k \in K
$$

According to constraint $(c)$, the intermodal freight conservation constraints, it is assumed that the rail-based intermodal system and the second-level rail-based intermodal system use the same freight train service and, accordingly, share the limited capacity (i.e., train slots). The assumption is similarly applied to two options of short sea shipping.

\section{SOLUTION PROCEDURE AND MODEL IMPLEMENTATION}

\section{Procedure}

\section{Estimation of Upper and Lower Bounds of Second Objective Function}

Step 0. Initialization: set all parameters; objective functions; and constraints $(a),(b),(c)$, and $(d)$.

Step 1. Run linear programming for $Z_{1}$ excluding $Z_{2}$ and get the initial solution for $Z_{1}$.

Step 2. Substitute the initial solution into $Z_{2}$ and assume that the current value of $Z_{2}$ is the upper bound of constraint $(e)$.

Step 3: Run linear programming for $Z_{2}$ with the same constraints excluding $Z_{1}$, get the initial solution for $Z_{2}$, and use the current value of $Z_{2}$ as the lower bound of constraint $(e)$.

\section{Estimation of Pareto Optimal Solution}

Step 4. Set the pareto optimal set equal to $\{\phi\}$ and the desired number of subsets of the pareto optimal points.

Step 5. Estimate the increment of $\mathrm{CO}_{2}$ : increment $=$ (upper bound - lower bound)/number of pareto optimal points.

Step 6. Update constraint (e)

$$
\begin{array}{r}
{\left[\sum_{k \in K} \sum_{(i, j) \in A} Q_{i j}^{k} x_{i j}^{k}+\sum_{k \in K} \sum_{i \in V} Q_{i}^{k} x_{i}^{k}+\sum_{k \in K} \sum_{j \in V} Q_{j}^{k} x_{j}^{k}\right]} \\
\leq(\text { initial upper bound - increment })
\end{array}
$$

Step 7. Run linear programming for $Z_{1}$ with the updated constraint and others.

Step 8. Update the subset of the pareto optimal set for $\left(Z_{1}, Z_{2}\right)$, if all constraints and optimality conditions are satisfied and a solution is found.

Step 9. If the current number of pareto optimal solutions is less than the desired number of pareto optimal solutions (in other words, the current upper bound is less than the global lower bound), go to Step 6 .

Step 10. End.

The Excel Solver program was used to run the linear programming for the entire algorithm. The algorithms have been coded in Visual Basic. The Lingo (version 11.0) program was also used for the verification.

\section{Case Study}

\section{Study Area}

The authors looked for a case study area where three different intermodal systems could be compared. The freight systems in the study area needed to have the appropriate equipment for transshipment and 
could compete, at least potentially, with each other. The study area also needed to have more than two major centers of economic activity. Two possibilities were the Port of Gdansk (Poland) and the Port of Rotterdam (the Netherlands). As many manufacturing industries have recently been located in Eastern Europe, the Port of Gdansk is one of the fastest-growing ports, is a regional hub for Poland and Lithuania, and is also connected to a freight rail-line. The Port of Rotterdam is one of the largest ports in Western Europe as well as a regional hub for the Netherlands and northern Belgium. Thus, by connecting the two ports (i.e., rail and short sea) as a long-haulage line, these two hubs make up an appropriate study area and satisfy the criteria mentioned above. This route has actually been recognized as one of the major freight corridors in Europe (11).

\section{Ranking of Costs and Emissions}

The freight transportation cost and $\mathrm{CO}_{2}$ emissions, as shown in Table 1, are estimated on the basis of two European Commission research studies: RECORDIT (12) and MEET (13), respectively. Although many factors affect $\mathrm{CO}_{2}$ emissions, the most crucial one for the long-distance trips in this case study is the average cruising speed rather than the acceleration rate, cold-start emissions, ambient temperature, and so on. Thus, $\mathrm{CO}_{2}$ emissions are estimated as a function of cruising speed and the distance traveled, with the average values being used for other factors, such as cold-start emissions and ambient temperature. This case study assumes that the average cruising speeds of trucks, railway, and short sea shipping are $90 \mathrm{~km} / \mathrm{h}$ (60 km/h in drayage), $90 \mathrm{~km} / \mathrm{h}$, and $25 \mathrm{~km} / \mathrm{h}$, respectively. It is also worth noting that production emissions are included on the basis of previous research (14-16). Those performance measures (i.e., costs and $\mathrm{CO}_{2}$ emissions) used as parameters in linear programming (i.e., $C_{i j}^{k}$ and $Q_{i j}^{k}$ ) are multiplied by the estimated shortest path distance on the basis of different modal networks (i.e., road, rail, and short sea waterway) in a geographic information system. Table 1 shows the complexity required to determine the best option in the network in terms of one of two objectives and the difficulty with the generalization of the freight costs for each freight system. In other words, one mode may dominate one route (region), whereas that mode may not even be comparable on another route (region). In addition, one mode may be economically superior to the others on one route, whereas it may be significantly worse on the other route. In the entire case study network, one fact that is certain is the worst freight system regarding $\mathrm{CO}_{2}$ emissions is the truck-only system indicated as (1) as shown in Table 1.

There are three types of drayage in the mode choice sets in Table 1: truck drayage, rail drayage, and truck pickup and distribution. The rationale dividing these types is that the distance of drayage in the study area seems to be longer than the practical drayage distance (i.e., $50 \mathrm{~km}$ or so). Truck drayage is defined as the movement from senders to a terminal or a port by trucks. It exists in the rail-based intermodal system (indicated by (2)) and the short sea based-intermodal system (indicated by (3)). Rail drayage (indicated by (4) and defined as the rail-rail (or rail-short sea shipping) connection system from the local freight train terminal to a hub terminal is shown in the second-level intermodal systems, and the rail-short sea-based intermodal system is indicated by (5). Thus, in the cases of the second-level intermodal systems, truck pickup and distribution plays the role of picking up from the origin and distributing to the destinations.

Mode choice (4) shows a cost performance that is quite competitive in terms of both freight costs and $\mathrm{CO}_{2}$ emissions. Compared with (2), (4) has a lower freight cost and lower $\mathrm{CO}_{2}$ emissions, although the terminal transshipment charges are twice as high. However, the route from Amsterdam to Warsaw (Route 1-3) was an exception. Both the rail- and short sea-based intermodal shortest path associated with the route involve a considerable detour, whereas the truck-only system (1) has the shortest path without such a considerable detour. Thus, the truck-only system is the best option on Route 1-3 in terms of costs. In practice, there are several similar cases, in that the truck-only system has a significant competitive advantage over the intermodal system because of the detour on the given network.

\section{Network Assignment}

The demand for containers in each node and furthermore the origindestination (O-D) matrices were estimated by using the freight

TABLE 1 Ranking of Costs and $\mathrm{CO}_{2}$ Emissions in Freight Network in Case Study

\begin{tabular}{|c|c|c|c|c|c|c|c|c|c|c|}
\hline \multirow[b]{2}{*}{ Origin-Destination } & \multicolumn{5}{|c|}{ Best Choice Based on Freight Transport Cost } & \multicolumn{5}{|c|}{ Best Choice Based on $\mathrm{CO}_{2}$} \\
\hline & Best Choice & 2 nd & $3 \mathrm{rd}$ & 4th & Worst Choice & Best Choice & 2nd & 3 rd & 4th & Worst Choice \\
\hline $\begin{array}{l}\text { Amsterdam, Netherlands- } \\
\text { Warsaw, Poland (1-3) }\end{array}$ & (1) $(€ 1,401)$ & (4) & (2) & (5) & (3) $(€ 3,108)$ & (4) $(2,026 \mathrm{~kg})$ & (2) & (5) & (3) & (1) $(5,706 \mathrm{~kg})$ \\
\hline $\begin{array}{l}\text { Amsterdam-Vilnius, } \\
\text { Lithuania }(1-4)\end{array}$ & (4) $(€ 1,596)$ & (1) & (2) & (5) & (3) $(€ 3,501)$ & (4) $(2,251 \mathrm{~kg})$ & (5) & (2) & (3) & (1) $(7,742 \mathrm{~kg})$ \\
\hline Amsterdam-Gdansk (1-6) & (4) $(€ 1,090)$ & (2) & (1) & (3) & (5) $(€ 2,607)$ & (4) $(1,435 \mathrm{~kg})$ & (2) & (5) & (3) & (1) $(5,271 \mathrm{~kg})$ \\
\hline $\begin{array}{l}\text { Brussels, Belgium- } \\
\quad \text { Warsaw }(2-3)\end{array}$ & (4) $(€ 1,484)$ & (1) & (2) & (5) & (3) $(€ 3,260)$ & (4) $(2,089 \mathrm{~kg})$ & (2) & (5) & (3) & (1) $(6,159 \mathrm{~kg})$ \\
\hline Brussels-Vilnius (2-4) & (4) $(€ 1,639)$ & (1) & (2) & (5) & (3) $(€ 3,653)$ & (4) $(2,314 \mathrm{~kg})$ & (5) & (2) & (3) & (1) $(8,195 \mathrm{~kg})$ \\
\hline Brussels-Gdansk (2-6) & (4) $(€ 1,169)$ & (2) & (1) & (5) & (3) $(€ 2,740)$ & (4) $(1,501 \mathrm{~kg})$ & (2) & (5) & (3) & (1) $(5,725 \mathrm{~kg})$ \\
\hline Rotterdam-Warsaw (5-3) & (4) $(€ 1,230)$ & (2) & (1) & (5) & (3) $(€ 2,917)$ & (4) $(1,703 \mathrm{~kg})$ & (2) & (5) & (3) & (1) $(5,852 \mathrm{~kg})$ \\
\hline Rotterdam-Vilnius (5-4) & (4) $(€ 1,385)$ & (2) & (1) & (5) & (3) $(€ 3,310)$ & (4) $(1,928 \mathrm{~kg})$ & (5) & (2) & (3) & (1) $(7,884 \mathrm{~kg})$ \\
\hline Rotterdam-Gdansk (5-6) & (2), (4) (€915) & & (1) & (3), & $€ 2,397)$ & (2), (4) $(1,114 \mathrm{~kg})$ & & (3), (5) & & (1) $(5,413 \mathrm{~kg})$ \\
\hline
\end{tabular}

NoTE: 1 euro = \$1.41700 in 2009 dollars, Aug. 2009. Mode (system) choice sets: (1) Truck-only system; (2) Rail-based intermodal system (truck drayage-rail long haulage-truck drayage); (3) Short sea-based intermodal system (truck drayage-shortsea haulage-truck drayage); (4) 2nd level rail-based intermodal system (truck pickup-rail drayage-rail long haulage-rail drayage-truck distribution); and (5) Rail-shortsea-based intermodal system (truck pickup-rail drayage-shortsea long haulage-rail drayage-truck distribution). 
transportation demand statistics issued by Eurostat (17). The summation of the demands for each arc was used as the right-hand side (RHS) constraints $\left(o_{i j}^{k}\right)$. The external flows and implicit internal flows were not considered in the case study (e.g., external containers to be loaded or unloaded in the Port of Rotterdam were not taken into account). The issue on setting up the capacity, in particular for the road network, is quite challenging because the situation on road links (e.g., the number of lanes, the percentages of freight and passenger trips, and time variations) varies from country to country in Europe. Thus, instead of setting up infrastructure capacity, the number of available freight vehicles in the logistics market is assumed to be that used in the RHS. For example, $x_{12}^{1}+x_{13}^{1}+\cdots+x_{99}^{1} \leq$ the number of trucks in the entire network region (the superscripts indi- cate the freight system). This may be applied to each node if the market information is sufficiently satisfied.

Figure $2 a$ shows the demand. Each arc has three mode options. Invisible arcs connect the spoke nodes (i.e., Nodes 1, 2, 3, and 4) and hubs (i.e., Hubs 5 and 6). Those arcs have two mode options, road and rail, because second intermodal systems are considered. The capacities for freight systems in the network are assumed to be 90 20-ft equivalent units (TEU) per day for rail; 200 TEU per day for short sea service; and 500 TEU for a truck-only system, which reflects the current freight system. Figure $2 b$ is the first container assignment solution that minimizes the freight cost in the network by the single linear programming running (i.e., Step 1 above). This solution may represent the current freight market share if the inputs

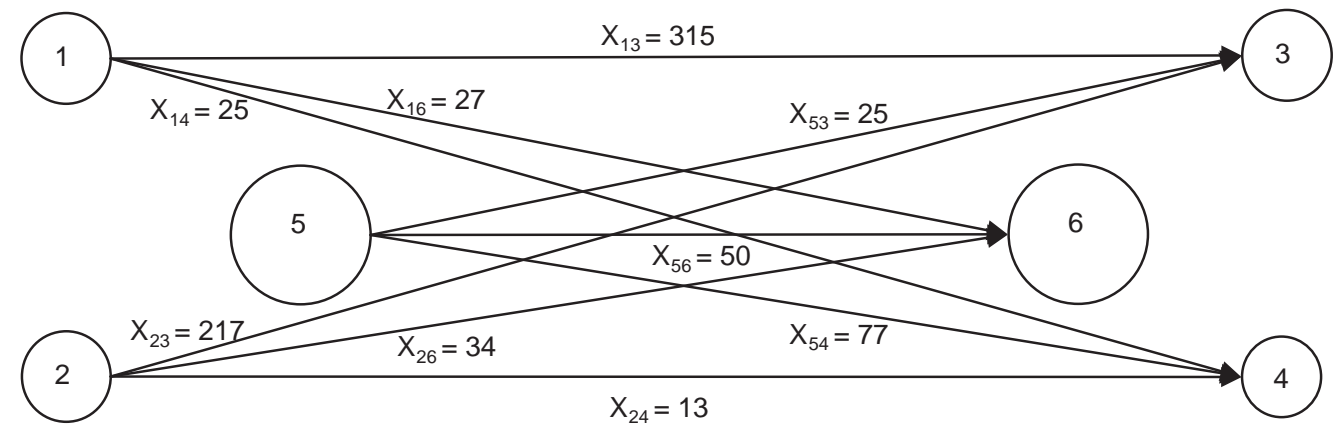

(a)

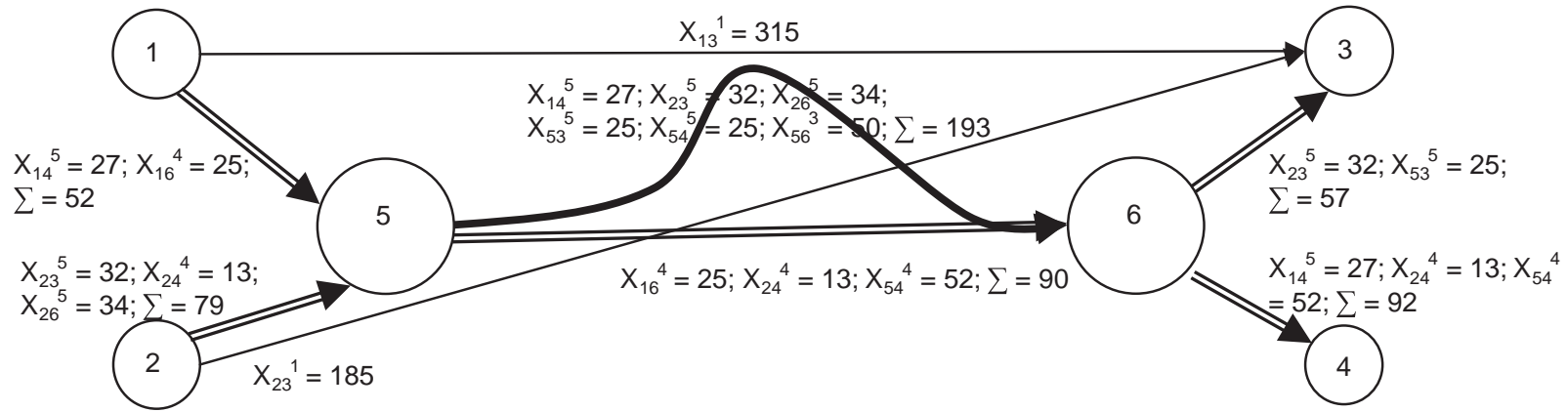

(b)

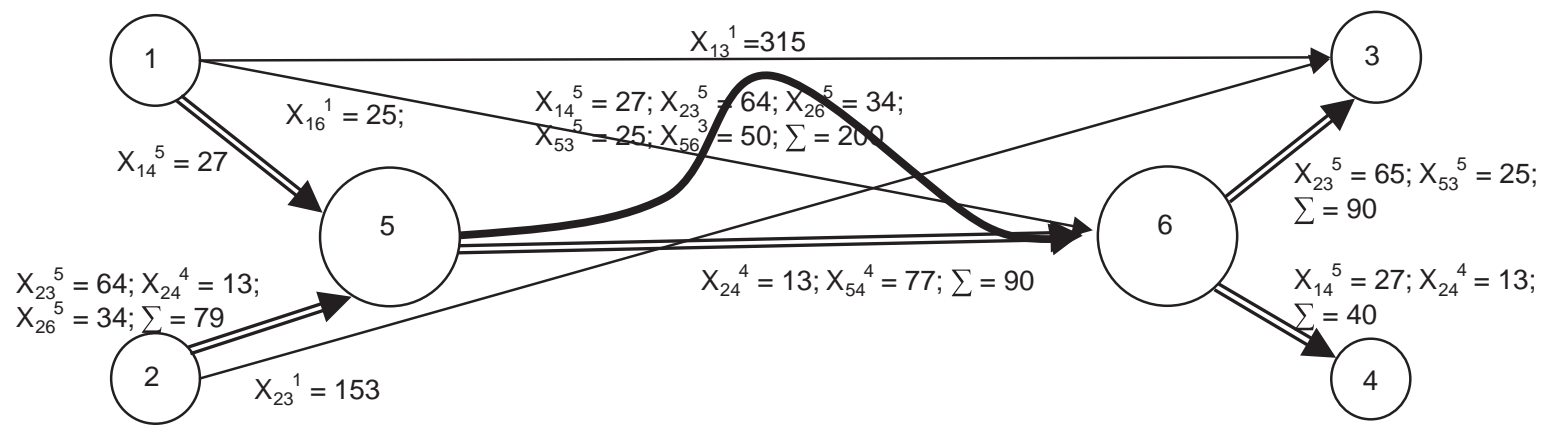

(c)

$\longrightarrow$ Highway $\longrightarrow$ Railway

FIGURE 2 Flows and initial assignment solutions: $(a$ ) input as container flows (demand), $(b)$ output as mode share and assignment based on the minimization of cost, and $(c)$ output as mode share and assignment based on the minimization of $\mathrm{CO}_{2}$ emissions. 
(i.e., demand and capacity) are accurate and the decisions in logistics are made only to minimize the freight cost. In addition, this solution is totally independent of the relation to $\mathrm{CO}_{2}$ because at present there is no direct regulation of $\mathrm{CO}_{2}$ emissions in the case study area.

Figure $2 c$ shows the assignment of containers in terms of minimizing the $\mathrm{CO}_{2}$ emissions generated from the freight systems in the entire network (i.e., Step 3 above). There are only a few shifts from one system to another to reduce $\mathrm{CO}_{2}$ emissions in the entire network. Specifically, for $\operatorname{Arc}(2,3)$, the 185 containers transported by road in Figure $2 b$ are reduced to 153 containers in Figure $2 c$ and are shifted to short sea shipping. However, because the short sea shipping has the capacity (i.e., 200 TEU per day), 25 containers from Node 5 to Node 4 are shifted from short sea shipping to rail, in that $X_{54}^{5}+X_{54}^{4}$ in Figure $2 b$ is equal to $X_{54}^{4}$ in Figure $2 c$. In terms of satisfying the flow conservation constraint [constraint $(a)$ above], this model appears to find the lowest costs and also ensures the lowest $\mathrm{CO}_{2}$ emissions. As shown in Table 1, the truck-only system for $\operatorname{arc}(1,6)$ seemed to be the optimal choice in terms of costs if railrelated services are excluded. This small change in the case study was because the capacities of each freight system are quite tight (i.e., the total demand and capacity are assumed to be 783 and 790 TEU, respectively). In other words, there is no significant room to update the network. It was also shown that the binding constraints in Figure $2 b$ were the truck-only system and the intermodal rail system, whereas in Figure $2 c$ the binding constraints were the railbased intermodal systems and the short sea-based intermodal systems. It is also worth noting that the flows with superior truck-only system costs in $\operatorname{Arc}(1,3)$ are supposed to shift to less $\mathrm{CO}_{2}$-emitting systems in Figure $2 b$. However, the capacities of other intermodal systems are full. It is recognized that the capacity and demand of intermodal systems seem to be crucial in terms of minimizing $\mathrm{CO}_{2}$ emissions. This issue will be fully discussed in the analysis of the scenario.

\section{Pareto Optimal (Trade-Off] Solution}

The solutions to the assignment problem estimated previously were the marginal points, as shown in Figure 3: the minimization of freight transportation system costs (i.e., the upper left side) and the minimization of $\mathrm{CO}_{2}$ emissions (i.e., the lower right side). Figure 3 shows 50 solutions, but these are only a subset of the pareto optimal solutions. However, the algorithm can estimate less than 50 solutions because there might be nonfeasible solutions in iterations. The relationship between costs and $\mathrm{CO}_{2}$ emissions in the entire network is not exactly linear. The linearity of the pareto optimal solution is not necessary, even if all the objective functions are linear. Specifically, the changed cost amounts are not necessarily proportional as the $\mathrm{CO}_{2}$ emissions allowed are decreased.

\section{SCENARIO ANALYSIS}

\section{Input Scenarios}

To examine different market situations, six different scenarios related to demand and capacity are shown in Table 2 .

Scenario 1 (S1), for which the pareto optimal solution is presented in Figure 3, is more or less the base scenario for comparison with the others. Thus, $\mathrm{S} 2$ and $\mathrm{S} 3$ are attempts to examine the change in the relationship between freight costs and $\mathrm{CO}_{2}$ emissions as the capacities of a specific freight system(s) are changed. More specifically, the two different demand scenarios are applied to the three different capacity options: current capacity (i.e., 500 TEU for trucks, 90 TEU for rail, and 200 TEU for vessels), three times increased rail capacity (i.e., 500 TEU for trucks, 270 TEU for rail, and 200 TEU for vessels), and an infinite capacity option.

In S4 to S6, the fixed number of containers (i.e., 87 containers) is the total number of containers divided by the number of nodes in the network region. These scenarios have been designed to avoid the effect of one exceptional route, which is Amsterdam to Warsaw. The route has greater demand (i.e., 315 containers) than the other nodes and an exceptionally cheaper truck-only system cost compared with those of the other arcs. In general, even though the demand might be correlated with the costs, it is assumed that the same numbers of containers are transported.

\section{Results}

The $x$-axes and the $y$-axes in the trade-off graphs (i.e., the pareto optimal solution) in Figure 4 have the same scale in each panel. Figure 3 was changed to the first graph (S1) for comparison with the other scenarios. Pairs of two scenarios, S1 and S4, S2 and S5, and $\mathrm{S} 3$ and S6, have similar shapes. Comparisons and interpretations are as follows:

- $\mathrm{S} 1$ versus $\mathrm{S} 2$. The increments of $\mathrm{CO}_{2}$ emission constraints of $\mathrm{S} 1$ and $\mathrm{S} 2$ are 527.16 and 10,941.28, respectively (the increment is

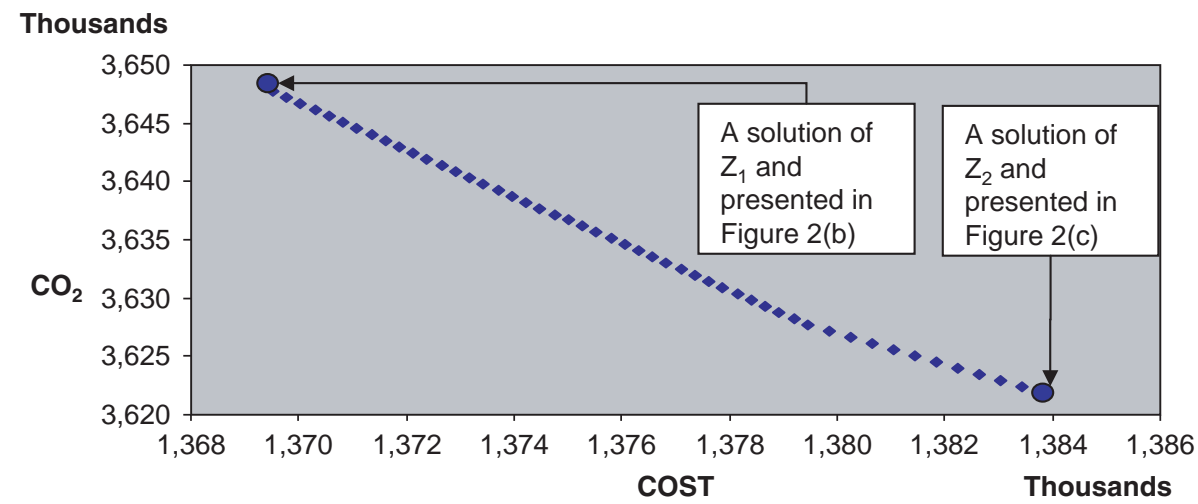

FIGURE 3 Pareto optimal solutions for S1. 
TABLE 2 Scenarios in Terms of O-D Flows and Service Capacity

\begin{tabular}{|c|c|c|c|c|c|c|c|c|}
\hline & Description & O-D Sets & & & & $\begin{array}{l}\text { Total } \\
\text { Demand }\end{array}$ & $\begin{array}{l}\text { Service } \\
\text { Mode }\end{array}$ & Capacity \\
\hline S1 & $\begin{array}{l}\text { Demand based on economic activity (Ams.-War./Bru.-War.) } \\
\text { and the capacity reflecting current market situation (two train } \\
\text { services per week and one short sea service per week) }\end{array}$ & $\begin{array}{l}\text { Amsterdam } \\
\text { Brussels } \\
\text { Rotterdam }\end{array}$ & $\begin{array}{l}\text { Warsaw } \\
315 \\
217 \\
25\end{array}$ & $\begin{array}{l}\text { Vilnius } \\
27 \\
13 \\
77\end{array}$ & $\begin{array}{l}\text { Gdansk } \\
25 \\
34 \\
50\end{array}$ & 783 & $\begin{array}{l}\text { Truck } \\
\text { Rail } \\
\text { Vessel }\end{array}$ & $\begin{array}{r}500 \\
90 \\
200\end{array}$ \\
\hline $\mathrm{S} 2$ & $\begin{array}{l}\text { Demand based on economic activity (Ams.-War./Bru.-War.) and } \\
\text { the extended intermodal capacity (three train services per } \\
\text { week and one short sea service per week) }\end{array}$ & $\begin{array}{l}\text { Amsterdam } \\
\text { Brussels } \\
\text { Rotterdam }\end{array}$ & $\begin{array}{l}\text { Warsaw } \\
315 \\
217 \\
25\end{array}$ & $\begin{array}{l}\text { Vilnius } \\
27 \\
13 \\
77\end{array}$ & $\begin{array}{l}\text { Gdansk } \\
25 \\
34 \\
50\end{array}$ & 783 & $\begin{array}{l}\text { Truck } \\
\text { Rail } \\
\text { Vessel }\end{array}$ & $\begin{array}{l}500 \\
270 \\
200\end{array}$ \\
\hline S3 & $\begin{array}{l}\text { Demand based on economic activity (Ams.-War./Bru.-War.) and } \\
\text { infinite capacity }\end{array}$ & $\begin{array}{l}\text { Amsterdam } \\
\text { Brussels } \\
\text { Rotterdam }\end{array}$ & $\begin{array}{l}\text { Warsaw } \\
315 \\
217 \\
25\end{array}$ & $\begin{array}{l}\text { Vilnius } \\
27 \\
13 \\
77\end{array}$ & $\begin{array}{l}\text { Gdansk } \\
25 \\
34 \\
50\end{array}$ & 783 & $\begin{array}{l}\text { Truck } \\
\text { Rail } \\
\text { Vessel }\end{array}$ & $\begin{array}{l}\text { Infinite } \\
\text { Infinite } \\
\text { Infinite }\end{array}$ \\
\hline S4 & $\begin{array}{l}\text { Fixed demand for all origins and the capacity reflecting the } \\
\text { current market situation (two train services per week and } \\
\text { one short sea service per week) }\end{array}$ & $\begin{array}{l}\text { Amsterdam } \\
\text { Brussels } \\
\text { Rotterdam }\end{array}$ & $\begin{array}{l}\text { Warsaw } \\
87 \\
87 \\
87\end{array}$ & $\begin{array}{l}\text { Vilnius } \\
87 \\
87 \\
87\end{array}$ & $\begin{array}{l}\text { Gdansk } \\
87 \\
87 \\
87\end{array}$ & 783 & $\begin{array}{l}\text { Truck } \\
\text { Rail } \\
\text { Vessel }\end{array}$ & $\begin{array}{r}500 \\
90 \\
200\end{array}$ \\
\hline S5 & $\begin{array}{l}\text { Fixed demand for all origins and extended capacity (three train } \\
\text { services per week and one short sea service per week) }\end{array}$ & $\begin{array}{l}\text { Amsterdam } \\
\text { Brussels } \\
\text { Rotterdam }\end{array}$ & $\begin{array}{l}\text { Warsaw } \\
87 \\
87 \\
87\end{array}$ & $\begin{array}{l}\text { Vilnius } \\
87 \\
87 \\
87\end{array}$ & $\begin{array}{l}\text { Gdansk } \\
87 \\
87 \\
87\end{array}$ & 783 & $\begin{array}{l}\text { Truck } \\
\text { Rail } \\
\text { Vessel }\end{array}$ & $\begin{array}{l}500 \\
270 \\
200\end{array}$ \\
\hline S6 & Fixed demand for all origins and infinite capacity & $\begin{array}{l}\text { Amsterdam } \\
\text { Brussels } \\
\text { Rotterdam }\end{array}$ & $\begin{array}{l}\text { Warsaw } \\
87 \\
87 \\
87\end{array}$ & $\begin{array}{l}\text { Vilnius } \\
87 \\
87 \\
87\end{array}$ & $\begin{array}{l}\text { Gdansk } \\
87 \\
87 \\
87\end{array}$ & 783 & $\begin{array}{l}\text { Truck } \\
\text { Rail } \\
\text { Vessel }\end{array}$ & $\begin{array}{l}\text { Infinite } \\
\text { Infinite } \\
\text { Infinite }\end{array}$ \\
\hline
\end{tabular}

Note: $\mathrm{S}=$ scenario; Ams. $=$ Amsterdam; War. $=$ Warsaw; Bru. $=$ Brussels.

defined in Step 5 above). The vertical length (i.e., $\mathrm{CO}_{2}$ emissions) and horizontal width (cost) of the two graphs can be explained by the amount of the increment. The greater increment means a longer and a wider graph, which indicates that the changeable amounts of the cost and $\mathrm{CO}_{2}$ emissions in $\mathrm{S} 2$ are relatively greater than those in $\mathrm{S} 1$. When it comes to an absolute comparison, it makes sense that S2, which adds two more railway services per day on long-haulage $\operatorname{Arc}(5,6)$ provides a more economical and less $\mathrm{CO}_{2}$-emitting service than $\mathrm{S} 1$ in the entire network region.

- $\mathrm{S} 1$ versus $\mathrm{S} 2$ versus $\mathrm{S} 3$. $\mathrm{S} 3$ shows that both costs and $\mathrm{CO}_{2}$ emissions are reduced as the capacity of the system is infinitely increased. Actually, the situation described on the graph does not happen in reality because of congestion on the highway and the queues of containers in ports and terminals. Nevertheless, it is worth observing that the slope of the graphs are different from those for S1 and $\mathrm{S} 2$. The shape indicates that it is feasible to reduce $\mathrm{CO}_{2}$ emissions drastically as relatively small costs are paid in the region where intermodal system capacities are sufficient and other external impacts are negligible.

- S1 versus S4. The slope of S4 is steeper than that of S1 because the concentration of demand in the area where a cheaper truck service (i.e., flows from Amsterdam) is provided is relaxed.

- S2 versus S5. The graph shapes are almost similar, apart from the left upper part of $\mathrm{S} 5$, the minimized cost with loosened $\mathrm{CO}_{2}$ constraints. That part indicates the slightly expensive freight costs because the costs are increased across the entire network through the uniform distribution of the demand (i.e., 87 containers for all nodes), in that some flows use uneconomical freight systems. The steeper slope at the beginning is because the truck-only system services rapidly shift to intermodal systems. As the uncompetitive expensive truck services in terms of route are removed from the network and the $\mathrm{CO}_{2}$ emissions constraints become tighter, the slope in S5 is stabilized, as in $\mathrm{S} 2$.
- $\mathrm{S} 3$ versus $\mathrm{S} 6$. In general, both costs and $\mathrm{CO}_{2}$ emissions are considerably decreased. The main reason is the initial unbalanced demand flows on $\operatorname{Arc}(5,6)$.

\section{DISCUSSION OF RESULTS}

Comparison of the scenarios in Figure 4 makes the evaluation of current tax policy possible. As mentioned previously, S1 was constructed on the basis of the current demand and capacity in the case study area. The slopes of each scenario in Figure 4 could be an indication of the $\mathrm{CO}_{2}$ tax price per ton because it is almost a line, which can be approximated at any point. Simple linear regressions are run to draw the generalized lines for six scenarios. Table 3 presents the scenarios, the estimated linear regression equations and $R^{2}$ values, and the price of $\mathrm{CO}_{2}$ per ton (in euros per ton of $\mathrm{CO}_{2}$ ). According to the $R^{2}$ values and the $t$-values (in brackets), the regression lines fit well. However, it is surprising that the price of $\mathrm{CO}_{2}$ ranges from 11 to $5,350 € /$ ton for the input scenarios. Considering the practically recommended price of $\mathrm{CO}_{2}$, which ranges from 7 to $45 € /$ ton for 2010 (18), even though the approach used to make that estimate is different from that used in this study, the price of $\mathrm{CO}_{2}$ estimated in this study seems to be overestimated. However, the opposite case is also possible, in that the currently recommended price of $\mathrm{CO}_{2}$ could be seriously underestimated.

\section{CONCLUSIONS AND FURTHER STUDY}

The quantitative relationship between $\mathrm{CO}_{2}$ emissions and freight costs has been gaining in importance in the logistics field because of global warming as well as rapidly increasing fuel costs. This study is an effort to estimate the relationship by use of the linear programming- 


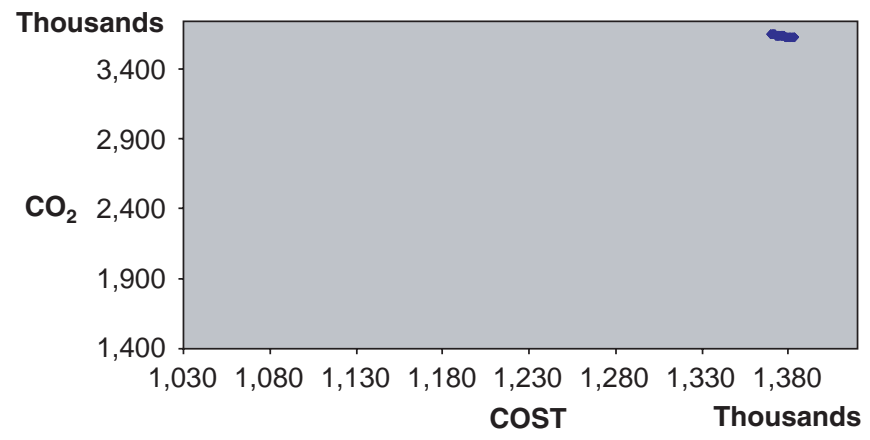

(a)

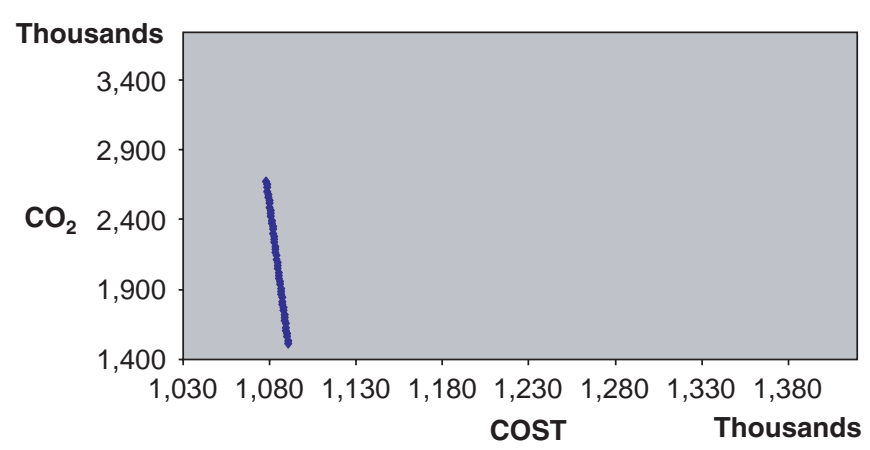

(c)

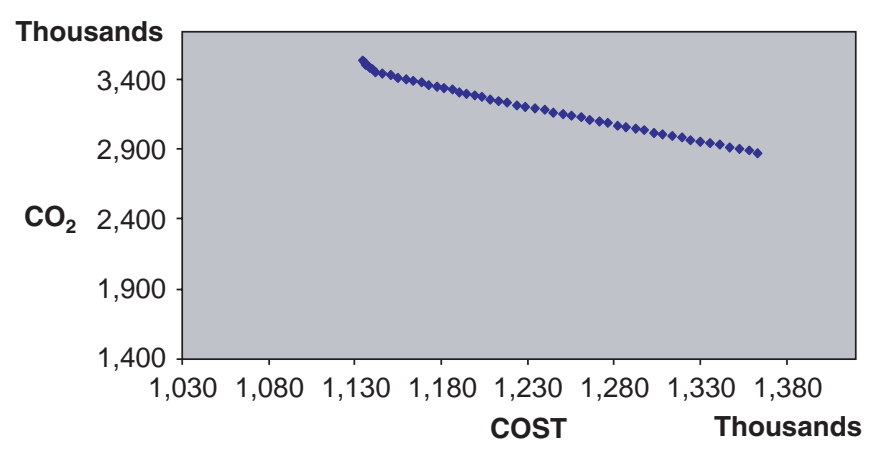

(e)

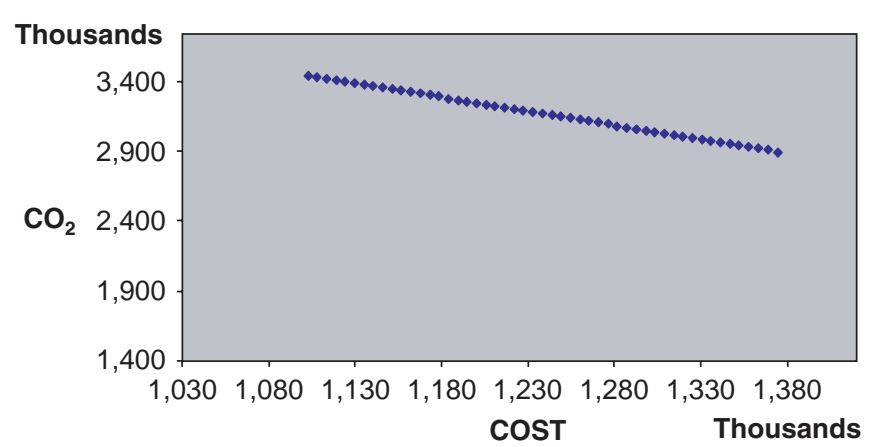

(b)

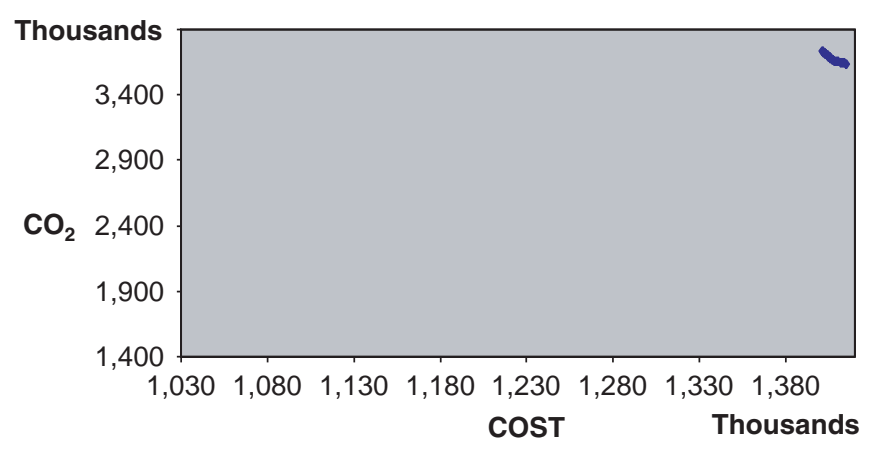

(d)

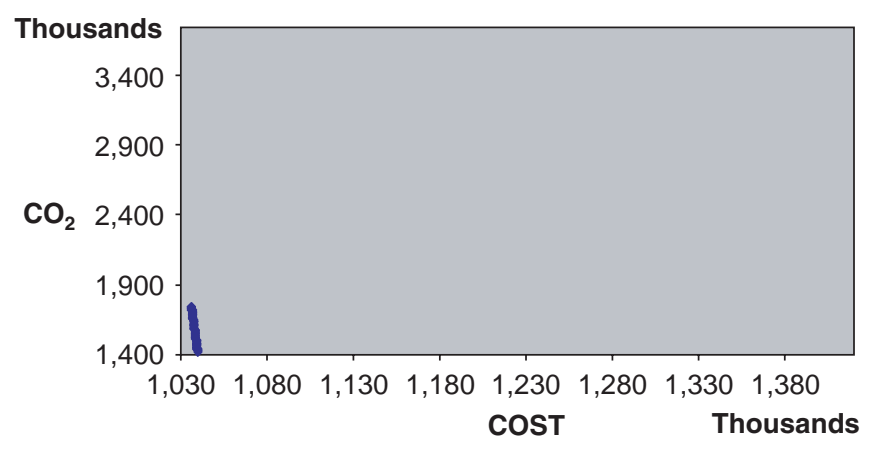

(f)

FIGURE 4 Scaled Pareto optimal solution for given network and demand: (a) S1, (b) S2, (c) S3, (d) S4, (e) S5, and ( $f$ ) S6.

based algorithm. This study clearly shows the trade-off curve generated by developing a decision-support tool. Because each solution composing the trade-off curve has an unique network assignment as well as modal share rate, the point (or range) that fits social needs or a decision makers' wishes can be found. Furthermore, examination of six scenarios with different O-D sets and capacity constraints shows that the trade-off curves have almost a linear relationship, in that freight costs should be higher as reduction of $\mathrm{CO}_{2}$ emissions is required. However, the quantity of the relationship varies, ranging from $€ 5,350$ to $€ 11$ per ton in terms of the input scenarios. In other words, the cost of $\mathrm{CO}_{2}$ emissions cannot be estimated in general, although it may be estimated only if several necessary conditions are fully considered (i.e., O-D sets, capacity and availability of freight systems, cost structure, estimates of $\mathrm{CO}_{2}$ emissions, and so on). The study also shows that increasing the lower $\mathrm{CO}_{2}$-emitting system's capacity would reduce $\mathrm{CO}_{2}$ emissions. In addition, this study has newly extended the concept of intermodality into second-level intermodal systems by assuming that drayage can be performed by rail and can be considered a different option.

Nevertheless, this study may be incomplete because one of the most crucial factors in logistics decision making, minimizing the lead time or ensuring just-in-time arrival (i.e., reliability), is not taken into account. The third and fourth objective functions could compensate for this incompleteness in a future study. The objective functions minimizing those temporal concepts might be nonlinear. In addition, the actual cost and emissions functions are not really linear. Although unit-based performance measures were used in this study, more precise formulations will lead this simple linear problem with feedback to a nonlinear optimization problem. Accordingly, nonlinear programming would be a better option as a means of finding a more accurate solution. Thus, more complicated algorithms such as evolutionary and generic algorithms should be used to estimate the full set of pareto optimal solutions. As mentioned above, the pareto optimal solution estimated in this study was a 
TABLE 3 Estimation of $\mathrm{CO}_{2}$ Price per Ton

\begin{tabular}{|c|c|c|c|c|}
\hline & Demand & Linear Regression Equation & $R^{2}$ & $\begin{array}{l}\mathrm{CO}_{2} \text { Price per } \\
\text { Ton }(€)\end{array}$ \\
\hline S1 & $\begin{array}{l}\text { Current O-D flows } \\
\text { Base capacity }\end{array}$ & $\begin{array}{l}\text { Cost }=3,319,039-5.35 \mathrm{CO}_{2} \\
{[-92.62]}\end{array}$ & .994 & 5,350 \\
\hline S2 & $\begin{array}{l}\text { Current O-D flows } \\
\text { Increased rail service }\end{array}$ & $\begin{array}{l}\text { Cost }=2,810,750-0.496 \mathrm{CO}_{2} \\
{[-7,945.5]}\end{array}$ & 1.000 & 496 \\
\hline S3 & $\begin{array}{l}\text { Current O-D flows } \\
\text { Infinite }\end{array}$ & $\begin{array}{l}\text { Cost }=1,107,040-0.011 \mathrm{CO}_{2} \\
{[-89,079.5]}\end{array}$ & 1.000 & 110 \\
\hline S4 & $\begin{array}{l}\text { Equal flows in all O-D } \\
\text { Base capacity }\end{array}$ & $\begin{array}{l}\text { Cost }=1,833,786-0.125 \mathrm{CO}_{2} \\
{[-23.4]}\end{array}$ & .919 & 125 \\
\hline S5 & $\begin{array}{l}\text { Equal flows in all O-D } \\
\text { Increased rail service }\end{array}$ & $\begin{array}{l}\mathrm{Cost}=2,414,230-0.368 \mathrm{CO}_{2} \\
{[-82.2]}\end{array}$ & .993 & 368 \\
\hline S6 & $\begin{array}{l}\text { Equal flows in all O-D } \\
\text { Infinite }\end{array}$ & $\begin{array}{l}\text { Cost }=1,055,150-0.011 \mathrm{CO}_{2} \\
{[-24,828.1]}\end{array}$ & 1.000 & 11 \\
\hline
\end{tabular}

subset. More details need to be provided in a future study. RECORDIT showed that the different types of loading units often caused considerably different total costs. Thus, although the two types of containers are converted into TEU in this study, attention should be paid to loading units. This is because the double size of a loading unit does not guarantee a double weight, which crucially affects costs as well as the $\mathrm{CO}_{2}$ emissions. Road traffic congestion is also an important factor affecting both costs and $\mathrm{CO}_{2}$ emissions. Specifically, congestion is mainly associated with the total traveled time for logistics costs; and accelerating, decelerating, and the number of stops are associated with $\mathrm{CO}_{2}$ emissions from freight transport. The severe road congestion in certain long-distance corridors would make the truck-only system less competitive than intermodal freight systems. The congestion in an intermodal terminal and port, one of the factors that makes the intermodal system less competitive, would also be considered in future studies.

\section{ACKNOWLEDGMENT}

The authors acknowledge the helpful discussions with Brian Park of the University of Virginia.

\section{REFERENCES}

1. Energy and Transport in Figures 2007. European Commission and Eurostat, Brussels, Belgium, 2007.

2. European Union Intermodal Transport: Key Statistical Data 1992-1999. European Commission, Brussels, Belgium, 2002.

3. Trends in the Transport Sector 1970-2004. European Conference of Ministers of Transport, Organisation for Economic Co-operation and Development, Paris, 2006.

4. European Transport Policy for 2010: Time to Decide. White Paper. European Commission, Brussels, Belgium, 2001.

5. Bontekoning, Y. M., C. Macharis, and J. J. Trip. Is a New Applied Transportation Research Field Emerging? A Review of Intermodal RailTruck Freight Transport Literature. Transportation Research, Part A, Vol. 38, 2004, pp. 1-34.
6. Deb, K. Multi-Objective Optimization Using Evolutionary Algorithms. John Wiley and Sons, Ltd., Chichester, United Kingdom, 2002.

7. Janic, M. Modelling Operational, Economical and Environmental Performance of an Air Transport Network. Transportation Research, Part D, Vol. 8, 2003, pp. 415-432.

8. Chang, Y. T., S. H. Shin, H. J. Kim, and P. Lee. Optimizing the Transportation of Container Cargoes in Korea Considering Environmental Costs. Presented at workshop on International Research Network under the auspices of the Asian Logistics and Round Table, Taoyuan, Taiwan, 2008.

9. Winston, W. L. Operations Research: Applications and Algorithms. Duxbury Press, Belmont, Calif., 1994.

10. Kim, N. S., and M. Janic. A New Framework of Air Pollution Quota for Limiting $\mathrm{CO}_{2}$ Emissions at the Multi-Modal Freight Transport Corridors. Presented at Trail Congress 2008, Rotterdam, Netherlands, 2008.

11. Walker, W. E., H. J. M. van Grol, S. A. Rahman, A. Lierens, and E. Horlings. Improving the Intermodal Freight Transport System Linking Western Europe with Central and Eastern Europe: Identifying and Prioritizing Policies. In Transportation Research Record: Journal of the Transportation Research Board, No. 1873, Transportation Research Board of the National Academies, Washington, D.C., 2004, pp. 109-119.

12. RECORDIT (Real Cost Reduction of Door-to-Door Intermodal Transport). European Commission, Brussels, Belgium, 2000.

13. Methodology for Calculating Transport Emissions and Energy Consumption-MEET. Project Report SE/491/98. European Commission, Brussels, Belgium, 1999.

14. Kim, N. S., and B. van Wee. Assessment of $\mathrm{CO}_{2}$ Emissions for Intermodal Freight Transport Systems and Truck-Only System: Case Study of Western-Eastern Europe Corridor. Presented at 88th Annual Meeting of the Transportation Research Board, Washington, D.C., 2009.

15. Facanha, C., and A. Horvath. Environmental Assessment of Freight Transportation in the U.S. International Journal of Life Cycle Assessment, Vol. 11, No. 4, 2006, pp. 229-239.

16. Spielmann, M., and R. W. Scholz. Life Cycle Inventories of Transport Services. International Journal of Life Cycle Assessment, Vol. 10, No. 1, 2005, pp. 85-94.

17. Eurostat Home Page. http://epp.eurostat.ec.europa.eu. Accessed Feb. 2008.

18. Handbook on Estimation of External Costs in the Transport Sector. Report 07.4288.52. Committed to the Environment, Delft, Netherlands, 2008.

The Freight Transportation Economics and Regulation Committee sponsored publication of this paper. 